\title{
Interpreting Markups in Spanish Manufacturing: The Exponential Model*
}

\author{
Luis C. Corchón, \\ Universidad Carlos III, Madrid. \\ Lourdes Moreno \\ Universidad Complutense, Madrid
}

First Draft: May 10 ${ }^{\text {nd }}$, 2008. This draft, November $2^{t h}, 2010$.

\begin{abstract}
In this paper we attempt to rationalize markups in a sample of Spanish manufacturing by assuming a representative consumer, profit-maximizing firms and constant returns to scale. We find that the standard forms of demand (CES and linear) do not provide a good explanation of markups. In contrast, a model where the representative consumer has an exponential utilty function yields results that match data more closely.
\end{abstract}

*We thank Carmen Beviá, Luis Cabral, Natalia Fabra, José María Sastre, Galina Zudenkova and the participants in a seminar at Carlos III University, especially Cesar Alonso and Paco Marhuenda, for very helpful comments, and Diego Rodríguez for programming support and data. The first author acknowledges financial support from ECO2008-02738/ECON. The second author acknowledges financial support from SEJ2007-66520/ECON. 


\section{Introduction}

This paper attempts to rationalize markups -price-marginal cost margins- by assuming a textbook model of industrial organization with a representative consumer, constant returns to scale, profit-maximizing firms and quantity competition. Assuming certain functional forms of demand -explained below- we derive first order conditions of profit maximization and transform them such that markups depend on observable variables. We regress the markups following the methodology used in Moreno and Rodriguez (2010b) with the corresponding observable variables. The data correspond to a panel of Spanish manufacturing firms for the period 1990-2005 obtained from the Encuesta Sobre Estrategias Empresariales (Survey on Business Strategies).

We first consider the most popular forms of demand, namely, CES, a combination of CES and linear, and CES with a subsistence level. We find that all these forms perform poorly when trying to explain markups in our sample: $R^{2}$ 's seldom go over .1, the explanatory variables are barely significant and when they are significant, they often have values that are inconsistent with the theory. The details can be found in the following tables and summaries provided below them: Tables 1a and 1b (for the CES model), Table 2 (for the CES-linear model) and Table 3 (for the CES with a subsistence level).

We present a functional form for utility which, to the best of our knowledge, is new in the field of imperfect competition, namely the exponential form. ${ }^{1}$ We assume that the representative consumer derives utility from a bundle of goods by means of a function which aggregates this bundle into a real number, call it $m$, and derives utility from $m$ in the form $-\frac{A}{B} e^{-B m}$ where $A$ and $B$ are positive numbers. We prove the existence and the uniqueness of equilibrium when firms face inverse demands that follow from these preferences, see Proposition 1.

From the empirical point of view, the exponential model implies that markups are an increasing function of output. When the product is homogeneous, this function is linear. We present empirical evidence that this model explains markups better than previous forms: the $R^{2}$ 's of all sectors are larger than in any estimation of previous forms and in most cases explanatory variables are significant -with values consistent with those predicted by theory- at $99 \%$ level, see Tables $4 \mathrm{a}, 4 \mathrm{~b}$ and 5 and the subsequent comments.

\footnotetext{
${ }^{1}$ This form has been used extensively in macroeconomics (see, e.g. Lucas, 1985) and welfare economics (see, e.g. Ray and Ueda, 1996),
} 
Next, we present a variation of the previous model which we call the exponential model Mark II. Now utility is derived as an exponential of a sum of quadratic terms involving outputs. In this case, markups are a quadratic function of output. From the theory point of view, this model presents two problems: The representative consumer has an atypical utility function and the second order condition of profit maximization (SOC) does not hold globally.

From the empirical point of view, this model fits data better than the previous exponential model: all $R^{2}$ 's are larger than in the exponential model and, again, most variables are significant at $99 \%$ with values consistent with those predicted by the theory. We also show that in $95 \%$ of the cases, SOC hold in the vicinity of output data for the estimated parameters.

A criticism of our procedure is that we perform a test of some functional forms by running regressions which involve, on the left hand side of the equations, markups, and on the right hand side, variables like outputs or prices. But both variables are determined jointly by profit maximization so our estimation procedure might be plagued with problems like endogeneity, etc.

A response to the previous criticism is that the models presented in this paper do not admit a closed form solution, except in the extreme case in which the product is homogeneous. This means that it is not possible to perform a test like the one explained in the previous paragraphs. All we can do is test if FOCs, which involve in a natural way the equalization between markups and the corresponding elasticities of inverse demand, are satisfied. Thus, our procedure can be seen as a preliminary test of the necessary conditions of equilibrium.

Our procedure is related to that of the so-called New Empirical Industrial Organization, Gollop and Roberts (1979), see Kim and Knittel (2006) for a recent entry and references on this literature. A difference with these papers is that we do not consider the degree of collusion but fucus on independent profit maximization, see our comments at the end of the paper.

The rest of the paper goes as follows. In Section 2 we explain our approach from both the theory and the empirical side. In Section 3 we test standard demand forms (CES and variations). In Section 4 we present the two exponential models and perform the relevant tests. Section 5 concludes and outlines some research paths. An Appendix explains the estimation of markups. 


\section{The Model}

In this section we present the common ingredients of the models used in this paper. We divide this section in two subsections devoted to explaining the theoretical model and the empirical implementation of the theoretical model respectively.

\subsection{The Theoretical Model}

There are $k$ sectors in the economy. A generic sector is composed of $n$ firms producing a single output each denoted by $x_{1}, x_{2}, \ldots, x_{n}$.

There is a representative consumer consuming goods $0,1,2, \ldots, n$ in quantities $M, x_{1}, x_{2}, \ldots, x_{n}$ at prices $1, p_{1}, p_{2}, \ldots, p_{n}$. Her preferences are representable by a quasi-linear utility function

$$
U=V\left(x_{1}, x_{2}, \ldots, x_{n}\right)+M
$$

where $V(\cdot)$ is strictly concave and three times continuously differentiable. The budget constraint of the representative consumer is $\sum_{i=1}^{n} p_{i} x_{i}+M=I$ where $I$ is her income, assumed to be exogenous. Substituting the value of $M$ in (1) and dropping $I$, which is just a constant, we obtain

$$
U=V\left(x_{1}, x_{2}, \ldots, x_{n}\right)-\sum_{i=1}^{n} p_{i} x_{i} .
$$

We will call (2) the consumer surplus. First order conditions of consumer surplus maximization yields inverse demand functions

$$
p_{i}=\frac{\partial V\left(x_{1}, x_{2}, \ldots, x_{n}\right)}{\partial x_{i}}, i=1,2, \ldots n .
$$

All firms have constant marginal costs denoted by $c_{i}$. Profits for firm $i$ denoted by $\pi_{i}$ are

$$
\pi_{i}=\frac{\partial V\left(x_{1}, \ldots, x_{n}\right)}{\partial x_{i}} x_{i}-c_{i} x_{i}, i=1,2, \ldots n .
$$

The markup for firm $i$, denoted by $\mu_{i}$, is defined as

$$
\mu_{i}=\frac{p_{i}-c_{i}}{p_{i}}
$$

We look for a Nash equilibrium in quantities where each firm maximizes profits taking the output of the other firms as given. Denoting equilibrium values with 
a star superindex, first order conditions of profit maximization are

$$
\frac{\partial V\left(x_{1}^{*}, \ldots, x_{n}^{*}\right)}{\partial x_{i}}+\frac{\partial^{2} V\left(x_{1}^{*}, \ldots, x_{n}^{*}\right)}{\partial x_{i}^{2}} x_{i}^{*}-c_{i}=0, i=1,2, \ldots n .
$$

From (3), (5) and (6) we obtain our fundamental equation:

$$
\mu_{i}=-\frac{\frac{\partial^{2} V\left(x_{1}^{*}, \ldots, x_{n}^{*}\right)}{\partial x_{i}^{2}} x_{i}^{*}}{\frac{\partial V\left(x_{1}^{*}, \ldots, x_{n}^{*}\right)}{\partial x_{i}}}, i=1,2, \ldots n . .
$$

Our research strategy is as follows. 1) We assume a parametric form of $V(\cdot)$ and find the corresponding Nash equilibrium. 2) We obtain an estimate for $\mu_{i}$ which does not depend on the characteristics of demand. 3) We estimate equation (7) and discuss the validity of this functional form.

\subsection{The Empirical Implementation}

In the Appendix we provide details of our estimation procedure. Here we only comment on the aspects that are essential for the understanding of the main text.

We estimate markups using the methodology of Roeger (1995). This approach allows us to obtain markups -by industry or by firm- estimating only one parameter and controlling for potential endogeneity of the productivity shocks.

The estimations are carried out using a panel of Spanish manufacturing firms for the period 1990-2005 obtained from the Encuesta Sobre Estrategias Empresariales (ESEE). Due to the fact that a long time period is available, we estimate individual markups for firms with at least nine observations. In this sense, we have one estimated markup for each firm. Specifically, we have information for 947 firms belonging to 20 manufacturing sectors.

We estimate equation (7) by cross-section data methodology. The independent variable is the previous estimated markup (or transformations of this variable according to the different specifications of $\mathrm{V}()$.$) . The dependent vari-$ ables that also vary with the theoretical specification are outputs, prices, market shares. Temporal averages of these variables are included as repressors.

Equation (7) is estimated for 15 manufacturing sectors. Although the original classification in the Appendix considers twenty sectors, in order to have a sufficient number of observations some sectors have been grouped together. 


\section{The CES Model and its Variants}

In this section we describe the pure CES model and two extensions of it. The case in which preferences can be represented by a utility function which has a CES part and a linear part (notice that this case subsumes the linear case as a special case), and the case of CES preferences with a minimum subsistence level.

\subsection{CES Preferences}

In this case preferences of the representative consumer are representable by a CES utility function

$$
U=F\left(\sum_{i=1}^{n} q_{i} x_{i}^{\rho}\right)+M, q_{i}>0, \rho \in(0,1),
$$

where $F(\cdot)$ is strictly concave and three times continuously differentiable and $q_{i}$ is interpreted as the quality of good $i$. In order to simplify the notation let $m \equiv \sum_{i=1}^{n} q_{i} x_{i}^{\rho}$. The inverse demand function for firm $i=1,2, \ldots, n$ is:

$$
p_{i}=\frac{d F(m)}{d m} q_{i} \rho x_{i}^{\rho-1}
$$

Profits for firm $i$ are

$$
\pi_{i}=\frac{d F(m)}{d m} q_{i} \rho x_{i}^{\rho}-c_{i} x_{i} .
$$

The first order condition of profit maximization for firm $i$ is

$$
\frac{d F(m)}{d m} q_{i} \rho^{2} x_{i}^{\rho-1}+\frac{d^{2} F(m)}{d m^{2}} q_{i}^{2} \rho^{2} x_{i}^{2 \rho-1}=c_{i} .
$$

Taking into account (5), (11) can be written as

$$
\frac{d^{2} F(m)}{d m^{2}} q_{i} \rho x_{i}^{\rho}=\frac{d F(m)}{d m}\left(1-\mu_{i}-\rho\right) .
$$

Define the elasticity of $\frac{d F(m)}{d m}$ with respect to $m$ as $\varepsilon=\frac{d^{2} F(m)}{d m^{2}} \frac{m}{\frac{d F(m)}{d m}}$. Taking this notation into account and rearranging (12), we obtain that

$$
\mu_{i}=1-\rho-\varepsilon \rho \frac{q_{i} x_{i}^{\rho}}{\sum_{i=1}^{n} q_{i} x_{i}^{\rho}}
$$


Equation (13) is difficult to estimate because of the non linear terms $x_{i}^{\rho}$. In order to get rid of these terms, we write (9) as

$$
p_{i} x_{i}=\frac{d F(m)}{d m} q_{i} \rho x_{i}^{\rho} .
$$

Adding over goods (14) we obtain,

$$
\sum_{i=1}^{n} p_{i} x_{i}=\rho \frac{d F(m)}{d m} \sum_{i=1}^{n} q_{i} x_{i}^{\rho} .
$$

and dividing (14) by (15) we obtain that

$$
\frac{p_{i} x_{i}}{\sum_{i=1}^{n} p_{i} x_{i}}=\frac{q_{i} x_{i}^{\rho}}{\sum_{i=1}^{n} q_{i} x_{i}^{\rho}} .
$$

Thus, equation (13) can now be written as

$$
\mu_{i}=1-\rho-\varepsilon \rho \frac{p_{i} x_{i}}{\sum_{i=1}^{n} p_{i} x_{i}} .
$$

When $p_{i} x_{i} / \sum_{i=1}^{n} p_{i} x_{i}$ is small (17) yields $\mu_{i} \simeq 1-\rho$ so we obtain the usual equation in which markups are constant.

Equation (17) can be estimated by making some assumptions ensuring that $\varepsilon$ is constant and running a linear regression between markups and $p_{i} x_{i} / \sum_{i=1}^{n} p_{i} x_{i}$. We have two subcases, each corresponding to a different assumption on $\varepsilon{ }^{2}$

The first case arises if $F(m)=\log (m), \varepsilon=-1$ and equation (17) is

$$
\mu_{i}=1-\rho+\rho \frac{p_{i} x_{i}}{\sum_{i=1}^{n} p_{i} x_{i}} .
$$

The second case arises if $F(m)=(m)^{\frac{r}{\rho}}$ with $r>0$ but $r \leq \rho$. In this case, $\varepsilon=(r-\rho) / \rho$ and equation $(17)$ is

$$
\mu_{i}=1-\rho+(\rho-r) \frac{p_{i} x_{i}}{\sum_{i=1}^{n} p_{i} x_{i}} .
$$

\footnotetext{
${ }^{2}$ We do not consider that $\rho^{\prime} s$ might be different for different firms because in this case it is not possible to transform $x_{i}^{\rho_{i}} / \sum_{j=1}^{n} x_{j}^{\rho_{j}}$ into $p_{i} x_{i} / \sum_{i=1}^{n} p_{i} x_{i}$. Indeed $p_{i} x_{i} / \sum_{i=1}^{n} p_{i} x_{i}=$ $\rho_{i} x_{i}^{\rho_{i}} / \sum_{j=1}^{n} \rho_{j} x_{j}^{\rho_{j}} \neq \rho_{i} x_{i}^{\rho_{i}} / \varrho \sum_{j=1}^{n} x_{j}^{\rho_{j}}$.
} 
In order to estimate equations (18) and (19) we write them as follows

$$
\mu_{i}=a+b \frac{p_{i} x_{i}}{\sum_{i=1}^{n} p_{i} x_{i}}
$$

with $a=1-\rho$ and $b=\rho$ in the case (18) and $b=\rho-r$ in the case of (19). Notice that if $\rho=r$, the expected value for the estimate of $b$ is zero. We present our results in Tables 1 and 1b. Table 1 offers our results for positive and negative markups. Since the latter are not compatible with the theoretical model, in Table 1b we consider only those firms with positive markups.

\section{INSERT TABLES $1 \mathrm{a}$ and $1 \mathrm{~b}$}

Consider the estimation for positive and negative markups. Firstly, the values of $a$ are, as predicted by the theoretical model, between 0.071 and 0.276 and they are significant at $100 \%$ in all sectors. But the market share is not significant for most sectors. ${ }^{3}$ The only two sectors which present a significant effect of this variable are Timber and Paper and Chemical. However the values of $b$ for both sectors -larger than one for Timber and Paper and negative for Chemicals- are not in accordance with the values predicted by the theoretical model (i.e. between zero and one). Therefore, our estimations yield an estimated $\rho$ which is approximately 1 minus the estimated average markups. Notice that the values of $R^{2}$ are small (even if we take into account that our regression is cross section) being larger than .1 only in Timber and Paper.

When we consider positive markups only, we find similar results. Firstly, the values of $a$ are between 0.178 and 0.305 and they are significant at $100 \%$ in all sectors. Secondly, as in the previous estimates, market shares are not significant in most sectors. For sectors where the market share is significant Timber and Paper, Chemicals, Fabricated Metal Products and Furniture - the estimated values for $b$ are not in accordance with the theoretical model. Thirdly, as expected, the values of $R^{2}$ are larger than in Table 1 when negative markups are considered but still smaller than 0.1 in most sectors. Finally, for the whole industry - the last rows of both Tables- we find the same results.

Summing up, the CES model with constant $\varepsilon$ estimated by OLS does not perform well in any sector of our sample. In the next two sections we will consider two extensions of the CES model.

\footnotetext{
${ }^{3}$ This result is compatible with $\rho$ equal to $r$.
} 


\subsection{The Linear-CES Model}

In this case, the utility function of the representative consumer is a sum of a CES and a linear utility function, namely

$U=F\left(\sum_{i=1}^{n} q_{i} x_{i}^{\rho}\right)+\alpha \sum_{i=1}^{n} x_{i}-\frac{\beta}{2} \sum_{i=1}^{n} x_{i}^{2}-\frac{\gamma}{2} \sum_{i=1}^{n} x_{i} \sum_{j \neq i} x_{j}+M, \beta>\gamma \geq 0, \alpha \geq 0$.

Under our assumptions

$$
p_{i}=\frac{d F(m)}{d m} q_{i} \rho x_{i}^{\rho-1}+\alpha-\beta x_{i}-\gamma \sum_{j \neq i} x_{j}, i=1,2, \ldots, n .
$$

Thus, profits of firm $i$ are

$$
\pi_{i}=\frac{d F(m)}{d m} q_{i} \rho x_{i}^{\rho}+\alpha x_{i}-\beta x_{i}^{2}-\gamma x_{i} \sum_{j \neq i} x_{j}-c_{i} x_{i} .
$$

To simplify the model we assume, as did Spence (1976), that when a firm maximizes profits it takes $m$ as given. The first order condition of profit maximization is

$$
\frac{d F(m)}{d m} q_{i} \rho^{2} x_{i}^{\rho-1}+\alpha-2 \beta x_{i}-\gamma \sum_{j \neq i} x_{j}=c_{i} .
$$

Multiplying both sides of (22) by $\rho$, using this equation and that $c_{i}=p_{i}\left(1-\mu_{i}\right)$, (24) is now

$$
\rho p_{i}-\rho \alpha+\rho \beta x_{i}+\rho \gamma \sum_{j \neq i} x_{j}+\alpha-2 \beta x_{i}-\gamma \sum_{j \neq i} x_{j}=p_{i}\left(1-\mu_{i}\right)
$$

or

$$
\mu_{i} p_{i}=-(1-\rho) \alpha+(1-\rho) p_{i}+\beta(2-\rho) x_{i}+(1-\rho) \gamma \sum_{j \neq i} x_{j}
$$

In order to estimate equation (25) we write it as follows

$$
\mu_{i} p_{i}=a+b p_{i}+d x_{i}+e \sum_{j \neq i} x_{j}
$$

with $a=-(1-\rho) \alpha, b=(1-\rho), d=\beta(2-\rho)$ and $e=(1-\rho) \gamma \cdot{ }^{4}$ We present our results for positive and negative markups in Table 2. Similar results (available upon request) are obtained when only positive markups are considered.

\footnotetext{
${ }^{4}$ Throughout the paper, abusing notation, we use lower case latin letters $a$ and $b$ to denote estimated parameters. Of course, the value and the meaning of these parameters change from equation to equation.
} 


\section{INSERT TABLE 2}

Firstly, the value of $b$ is consistent with the predictions of the theoretical model. The implicit values of $\rho$ tend to be smaller than the values of $\rho$ found in the previous estimation. Nevertheless, in this case the number of sectors for which this variable is significant is smaller than in the previous estimation. With respect to the rest of explanatory variables, the coefficients are non significant in almost all sectors and when they are significant the sign is not the one predicted by the theory. For the whole sample the sign of the coefficient associated with the output of rival firms is not the one predicted by the theory. ${ }^{5}$ The $R^{2}$ are low but tend to be larger than those obtained in the previous estimation.

Summing up, the Linear-CES model estimated by OLS does not perform well in any sector of our sample.

\subsection{The CES Model with a Subsistence Level}

We now consider another variation of a CES utility function namely

$$
U=F\left(\sum_{i=1}^{n} q_{i}\left(x_{i}-\bar{x}\right)^{\rho}\right)+M
$$

$\bar{x}$ is the minimum consumption of a brand (Brown and Heien, 1972). ${ }^{6}$ Defining $o \equiv \sum_{i=1}^{n} q_{i}\left(x_{i}-\bar{x}\right)^{\rho}$, the inverse demand function of good $i$ in this case is:

$$
p_{i}=\frac{d F(o)}{d o} q_{i} \rho\left(x_{i}-\bar{x}\right)^{\rho-1}, i=1,2, \ldots, n .
$$

Profits in this case are

$$
\pi_{i}=\frac{d F(o)}{d o} q_{i} \rho\left(x_{i}-\bar{x}\right)^{\rho-1} x_{i}-c_{i} x_{i} .
$$

The first order condition of profit maximization yields the following equation

$$
\frac{d F(o)}{d o} q_{i} \rho\left(x_{i}-\bar{x}\right)^{\rho-1}\left[1+\frac{\rho-1}{x_{i}-\bar{x}} x_{i}+\xi \rho x_{i} \frac{q_{i}\left(x_{i}-\bar{x}\right)^{\rho-1}}{\sum_{i=1}^{n} q_{i}\left(x_{i}-\bar{x}\right)^{\rho}}\right]=c_{i},
$$

\footnotetext{
${ }^{5}$ In any case, the sign predicted by the theory is counterintuitive because an increase in the output of rival firms should decrease the monopoly power and thus the markup of a firm.

${ }^{6} \bar{x}$ could be considered to be different for different goods but this will cause problems when we estimate the relevant equation, see (32) below.
} 
where $\xi$ is the elasticity of $\frac{d F(\cdot)}{d o}$ with respect to $o$. Taking into account (28) and the definition of $\mu_{i},(29)$ can be written as

$$
\mu_{i}=\frac{1-\rho}{x_{i}-\bar{x}} x_{i}-\xi \rho \frac{p_{i} x_{i}}{\sum_{i=1}^{n}\left(p_{i} x_{i}-p_{i} \bar{x}\right)} .
$$

Notice that when $\bar{x}=0,(30)$ reduces to (17). The equation (30) is non-linear and difficult to estimate so, as we did in the Linear-CES model, we will assume when a firm maximizes profits it takes $o$ as given. Thus $\xi=0$ and the last term in (30) disappears. Manipulating (30) we obtain that

$$
\frac{1}{\mu_{i}}=\frac{1}{1-\rho}-\frac{\bar{x}}{1-\rho} \frac{1}{x_{i}}
$$

Equation (31) relates the inverse of markups with the inverse of output. In order to estimate this equation we write it as follows:

$$
\frac{1}{\mu_{i}}=a+b \frac{1}{x_{i}} .
$$

with $a=\frac{1}{1-\rho}$ and $b=\frac{-\bar{x}}{1-\rho}$. We present our results for positive markups in Table 3. Due to the non-linearity of the specification, the results obtained by considering negative markups are not very relevant and are not presented.

\section{INSERT TABLE 3}

Notice that the coefficient associated with $a$ is significant in all sectors. The implicit value of $\rho$ lies between 0.8 and 0.963 so it agrees with the predictions of the theory. But the coefficient associated with $b$ is not significant in 12 out of 15 sectors. Moreover, $R^{2}$ are small, never exceeding .04. Summing up, the CES model with a subsistence level does not perform any better than previous models in explaining markups. 


\section{The Exponential Model}

In this section we present two models in which demand is an exponential function of outputs. In these models markups are a simple function of outputs.

\subsection{The Basic Exponential Model}

In this subsection we assume that the utility function takes the following form

$$
U=-\frac{A}{B} e^{-B m}+M, \quad A, B>0,
$$

where $m$ is the variable defined in subsection 3.1. Since, to the best of our knowledge, this is the first time that this model has been used in industrial organization, we provide a complete analysis of it.

Firstly, consider the maximization of consumer surplus. We readily see that second order conditions are satisfied. Thus, first order conditions of surplus maximization yield an optimum for the consumer, namely

$$
p_{i}=A q_{i} \rho e^{-B m} x_{i}^{\rho-1}, i=1, \ldots, n .
$$

Secondly, consider profit maximization. Profits for a typical firm, say $i$, are

$$
\pi_{i}=A q_{i} \rho e^{-B m} x_{i}^{\rho}-c_{i} x_{i}
$$

First order condition of profit maximization when $x_{i}>0$ are

$$
\frac{\partial \pi_{i}}{\partial x_{i}}=A q_{i} \rho^{2} e^{-B m} x_{i}^{\rho-1}-A B q_{i} \rho^{2} x_{i}^{\rho} e^{-B m} q_{i} x_{i}^{\rho-1}-c_{i}=0,
$$

which can be written

$$
A q_{i} \rho^{2} e^{-B m} x_{i}^{\rho-1}\left(1-B x_{i}^{\rho} q_{i}\right)-c_{i}=0
$$

The second order condition of profit maximization holds because the left hand side of (37) is decreasing in $x_{i}$. Also, when $x_{i} \rightarrow 0, \frac{\partial \pi_{i}}{\partial x_{i}} \rightarrow \infty$ so all firms produce a positive output. We now investigate the basic properties of equilibrium.

Proposition 1. The exponential model has a unique Nash equilibrium

Proof. By defining a new variable $y_{i} \equiv q_{i} x_{i}^{\rho}$, the game becomes aggregative, i.e. payoffs and first order conditions for each firm, say $i$, can be written in terms 
of $y_{i}$ and $\sum_{j=1}^{n} y_{j}$, indeed equations (35) and (36) become

$$
\begin{aligned}
\pi_{i} & =A \rho e^{-B \sum_{j=1}^{n} y_{j}} y_{i}-c_{i}\left(\frac{y_{i}}{q_{i}}\right)^{\frac{1}{\rho}} . \\
\frac{\partial \pi_{i}}{\partial x_{i}} & =A \rho e^{-B \sum_{j=1}^{n} y_{j}}\left(1-B y_{i}\right)-\frac{c_{i}}{\rho q_{i}^{\frac{1}{\rho}}} y_{i}^{\frac{1-\rho}{\rho}}
\end{aligned}
$$

We see that $\frac{\partial \pi_{i}}{\partial x_{i}}$ is decreasing in $\sum y_{j}$ given $y_{i}$ and decreasing in $y_{i}$ given $\sum y_{j}$. Thus, assumptions A1 and A2 in Corchón (1994) are satisfied. The compactness requirement also holds because $y_{i}$ can be taken such that $1 \geq B y_{i}$. Thus, as observed in Corchón op. cit. p. 156, the model has a unique equilibrium. ${ }^{7}$

Proposition 1 shows that the exponential model is amenable to analysis even though a closed form solution is, in general, hard to obtain since equation (36) is difficult to solve. In order to simplify our problem, in the rest of this section we set $q_{i}=1$ for all $i$. From the definition of a markup in (5) and (34), (36) can be written as

$$
\mu_{i}=1-\rho+B \rho x_{i}^{\rho} .
$$

First, let us estimate $\rho$. Consider the equation (34). Dividing by $p_{n}$ we get

$$
\frac{p_{i}}{p_{n}}=\left(\frac{x_{i}}{x_{n}}\right)^{\rho-1}, i=1, \ldots, n-1
$$

Taking logs, the previous equation can be written as

$$
\log \frac{p_{i}}{p_{n}}=(\rho-1) \log \frac{x_{i}}{x_{n}}, i=1, \ldots, n-1
$$

Thus, by running a linear regression between $\log \frac{p_{i}}{p_{n}}$ and $\log \frac{x_{i}}{x_{n}} i=1, \ldots, n-1$ we can estimate the value of $\rho$. With this value of $\rho$, say $\bar{\rho}$, we estimate equation (40) which we write as follows

$$
\mu_{i}-1+\bar{\rho}=a x_{i}^{\bar{\rho}}
$$

We present our estimation of $\rho$ in the first column of Tables 4a (for positive and negative markups) and $4 \mathrm{~b}$ (positive markups only).

\section{INSERT TABLES 4a AND 4b}

We see that the estimated values of $\rho$ are, in all sectors, very close to one. The estimated value of $a$ is shown in the first column. Notice the following:

\footnotetext{
${ }^{7}$ These properties also imply well-behaved comparative statics, see Corchón (1994).
} 
Firstly, the signs of the values of $a$ agree with those predicted by the theoretical model (i.e. positive). Secondly, the values of $a$ are highly significant except in Industrial and Agricultural Equipment (with positive markups). Thirdly the values of $R^{2}$ are relatively high (taking into account that our regression is cross section). The estimation appears particularly promising in the following four sectors: Meat Related Products, Timber and Paper, Basic Metal Products, Furniture and Leather, Fur and Footwear and Miscellaneous.

The previous result suggests that taking $\rho=1$, i. e. that goods in each sector are perfect substitutes, may be a good approximation, at least around equilibrium. ${ }^{8}$ In this case (40) becomes

$$
\mu_{i}=B x_{i}
$$

i.e. markups are a linear function of outputs. We now check the robustness of the previous estimation by testing the model imposing $\rho=1$ for all sectors. We write equation (44) as follows:

$$
\mu_{i}=a x_{i}
$$

with $B=a$. We present our results in Table 5 for both the case when positive and negative markups are considered and for the case when only positive markups are considered.

\section{INSERT TABLE 5}

Results here are very close to those presented before. Again, the explanatory variable is significant in all cases and in the four sectors mentioned before, the average of the $R^{2}$ in both estimations is larger than .175 and the explanatory variable is significant at $100 \%$. To further check the robustness of this result we estimate the model for $\rho=.95$ with identical results (available upon request).

\subsection{The Exponential Model, Mark II}

As we will see in a moment, the estimation improves by introducing a quadratic term in (45) so $\mu_{i}=B x_{i}-D x_{i}^{2}$, say. This can be rationalized as follows. Suppose that the inverse demand function for firm $i$ is

$$
p_{i}=A_{i}\left(x_{-i}\right) e^{-B x_{i}+\frac{D}{2} x_{i}^{2}}, A_{i}, B, D>0, i=1, \ldots, n,
$$

${ }^{8}$ The homogeneity assumption allows us to find an explicit solution of equilibrium. A proof of this assertion is available upon request. 
where $x_{-i}$ is a list of all outputs minus $i$ and $A_{i}(\cdot)$ is a function of $x_{-i}$. Under (46), profits for firm $i$ are

$$
\pi_{i}=A_{i}\left(x_{-i}\right) e^{-B x_{i}+\frac{D}{2} x_{i}^{2}} x_{i}-c_{i} x_{i} .
$$

We will call this model, the exponential model Mark II. First order condition of profit maximization (assuming interiority) is:

$$
\frac{\partial \pi_{i}}{\partial x_{i}}=A_{i}\left(x_{-i}\right) e^{-B x_{i}+\frac{D}{2} x_{i}^{2}}-A_{i}\left(x_{-i}\right) e^{-B x_{i}+\frac{D}{2} x_{i}^{2}}\left(B-D x_{i}\right) x_{i}-c_{i}=0,
$$

which can be written as

$$
A_{i}\left(x_{-i}\right) e^{-B x_{i}+\frac{D}{2} x_{i}^{2}}\left(1-B x_{i}+D x_{i}^{2}\right)-c_{i}=0 .
$$

From (46) and (49) we have that

$$
p_{i}\left(1-B x_{i}+D x_{i}^{2}\right)-c_{i}=0 .
$$

Now, from the definition of markup we obtain that

$$
\mu_{i}=B x_{i}-D x_{i}^{2},
$$

as desired. The reader can easily verify if $(51)$ holds for all $x_{i},(46)$ is the unique inverse demand function that yields (51).

The first problem of the exponential model Mark II is to find a representative consumer yielding (46). Our next result addresses this question.

Proposition 2. If there is a representative consumer yielding inverse demand functions as in (46) her preferences can be represented as

$$
U=\frac{e^{-\frac{1}{2} \frac{B^{2}}{D}} \sqrt{\pi}}{\sqrt{-2 D}} \prod_{i=1}^{n} \operatorname{erf}\left(\sqrt{\frac{-1}{2 D}}\left(-B+D x_{i}\right)\right)+M
$$

where $\operatorname{erf}(\cdot)$ is the so-called error function and

$$
A_{i}\left(x_{-i}\right)=\prod_{j \neq i}^{n} \operatorname{erf}\left(\sqrt{\frac{-1}{2 D}}\left(-B+D x_{j}\right)\right), i=1,2, \ldots, n .
$$

Proof. Consider $x_{-i}$ as given. Integrating (46) with respect to $x_{i}$ we obtain

$$
\begin{gathered}
V\left(x_{1}, x_{2}, \ldots, x_{n}\right)=\int A_{i}\left(x_{-i}\right) e^{-B x_{i}+\frac{D}{2} x_{i}^{2}} d x_{i} \\
=\frac{e^{-\frac{1}{2} \frac{B^{2}}{D}} \sqrt{\pi}}{\sqrt{-2 D}} A_{i}\left(x_{-i}\right) \operatorname{erf}\left(\sqrt{\frac{-1}{2 D}}\left(-B+D x_{i}\right)\right) .
\end{gathered}
$$


where $V(\cdot)$ has been defined in (1). In order to simplify notation set

$$
\frac{e^{-\frac{1}{2} \frac{B^{2}}{D}} \sqrt{\pi}}{\sqrt{-2 D}} \equiv \lambda \text { and } \operatorname{erf}\left(\sqrt{\frac{-1}{2 D}}\left(-B+D x_{i}\right)\right) \equiv f\left(x_{i}\right) .
$$

Since the previous argument works for any $i=1, \ldots, n$ we have a system of functional equations where the functions $V(\cdot)$ and $A_{i}(\cdot)$ are the unknowns, namely

$$
\begin{aligned}
V\left(x_{1}, x_{2}, \ldots, x_{n}\right)= & \lambda A_{1}\left(x_{-1}\right) f\left(x_{1}\right) \\
V\left(x_{1}, x_{2}, \ldots, x_{n}\right)= & \lambda A_{2}\left(x_{-2}\right) f\left(x_{2}\right) \\
& \ldots \ldots \ldots \\
V\left(x_{1}, x_{2}, \ldots, x_{n}\right)= & \lambda A_{n}\left(x_{-n}\right) f\left(x_{n}\right),
\end{aligned}
$$

A solution for the above system is

$$
A_{i}\left(x_{-i}\right)=\prod_{j \neq i}^{n} f\left(x_{j}\right) i=1,2, \ldots, n .
$$

Thus, the utility function in (52) is validated. Now since

$$
\begin{aligned}
\frac{\partial V\left(x_{1}, x_{2}, \ldots, x_{n}\right)}{\partial x_{i}} & =\lambda \frac{\partial f\left(x_{i}\right)}{\partial x_{i}} \prod_{j \neq i}^{n} f\left(x_{j}\right)=e^{-B x_{i}+\frac{D}{2} x_{i}^{2}} \prod_{j \neq i}^{n} f\left(x_{j}\right)= \\
p_{i} & =A_{i}\left(x_{-i}\right) e^{-B x_{i}+\frac{D}{2} x_{i}^{2}}
\end{aligned}
$$

and the inverse demand function is independent of the particular representation of preferences, it must be that

$$
A_{i}\left(x_{-i}\right)=\prod_{j \neq i}^{n} f\left(x_{j}\right)
$$

as desired.

Proposition 2 is a negative result because (52) is an atypical utility function and (53) yields atypical demand functions. Moreover, it can be shown that (52) is not concave (an example is available upon request). Thus, first order conditions might reflect just a local maximum. Finally, it is also not clear how to invert inverse demand functions to obtain demand functions except in very special cases. ${ }^{9}$

\footnotetext{
${ }^{9}$ For instance when $n=1$ and $2 D \log A_{1} \leq B^{2}$, the demand function exists.
} 
The second problem of the exponential model Mark II, is that the second order condition fails to be satisfied globally. Indeed, computing,

$$
\begin{aligned}
\frac{\partial p_{i}}{\partial x_{i}} & =\left(-B+D x_{i}\right) p_{i} \\
\frac{\partial^{2} p_{i}}{\partial x_{i}^{2}} & =D p_{i}+\left(-B+D x_{i}\right) \frac{\partial p_{i}}{\partial x_{i}}
\end{aligned}
$$

Taking into account (56), (57) can be written as

$$
\frac{\partial^{2} p_{i}}{\partial x_{i}^{2}}=D p_{i}+\left(-B+D x_{i}\right)^{2} p_{i}
$$

Second order conditions of profit maximization are

$$
2 \frac{\partial p_{i}}{\partial x_{i}}+\frac{\partial^{2} p_{i}}{\partial x_{i}^{2}} x_{i}<0
$$

Taking into account (56) and (58), (59) can be written as

$$
2\left(-B+D x_{i}\right)+D x_{i}+\left(-B+D x_{i}\right)^{2} x_{i}<0 .
$$

Now using (51), (60) can be written as

$$
\mu_{i}\left(\mu_{i}-2\right)+D x_{i}^{2}<0
$$

which is the equation to be checked. Clearly (61) cannot hold for all $x_{i}$ because for output close to infinity, the expression on the left hand side is positive.

We test equation (51). In the notation used in previous sections,

$$
\mu_{i}=a x_{i}+b x_{i}^{2}
$$

where $a=B$ and $b=-D$. Results are given in Tables $6 \mathrm{a}$ and $6 \mathrm{~b}$ below for the cases of only positive markups and positive and negative markups respectively. We also test if second order conditions hold for the estimated values of $\mu_{i}$ and $D$ and for the data on $x_{i}$. Thus, we test if firms are maximizing profits locally. ${ }^{10}$

\section{INSERT TABLES 6a AND 6b HERE}

\footnotetext{
${ }^{10}$ If firms maximize profits locally we have at least three interpretations of the behavior of firms. 1) Firms are just local maximizers, Silvestre (1979). 2) Firms maximize globally but with capacity constraints.3) Firms maximize globally, but the form of the demand function is locally but not globally the exponential.
} 
We see that the estimated values of $B$ are significant at $99 \%$ in twelve sectors and the aggregate. They are significant at $95 \%$ in three sectors. The estimated values of $D$ are significant at $99 \%$ in seven sectors and the aggregate. They are significant at $95 \%$ in five sectors. All $R^{2}$ 's are higher than the previous estimation; SOC never hold when $\mu_{i}<0$. When $\mu_{i}>0$ SOC hold locally in $94.6 \%$ of cases when $\mu_{i}>0$. Summing up, the exponential model estimated by OLS performs quite well in a relatively large number of sectors in our sample. This model seems to be a reasonable starting point for understanding markups in several sectors of our sample.

\section{CONCLUSIONS}

In this paper we have presented a new functional form, namely the exponential one, which explains FOC better than standard forms like CES, linear, etc. for a sample of Spanish manufacturing data. Our model relies on assumptions like quantity competition, quasi-linear utility and stable preferences that must be subject to further inquiry before definitive conclusions are drawn. We also do not consider factors that are likely to play an important role in the determination of markups such as Collusion (Bresnahan, (1989)), International Trade (Melitz and Ottaviano (2008), Feenstra and Kee (2008), De Loecker and Warzynski, 2009, Moreno and Rodriguez (2010a) and non-linear pricing (Miravete and Röller (2004)). Our model is admittedly simple but might serve as a useful starting point for future endeavours.

Summing up, the exponential models presented in this paper are workable and provide us with a new tool to analyze markets characterized by imperfect competition.

We emphasize that our paper cannot be construed as a criticism of linear or CES models. On the contrary, the exponential model presented in this paper must be considered as a new addition to the toolbox of Industrial Economics that might be useful in some instances and should not be regarded as a competitor, but rather as a complement to other models. 


\section{Appendix: Estimation of Markups}

\subsection{Methodology}

To estimate the firm's markups we use the methodology proposed by Roeger (1995). Some papers have used this approach to analyze the effect of trade liberalziation on markups (see, for example Konings et al. (2005a \& 2005b)). This approach starts with a production function which is linear homogeneous in the inputs:

$$
x_{i t}=A_{i t} F\left(L_{i t}, M_{i t}, K_{i t}\right)
$$

where $x_{i t}$ is the output, $L_{i t}, M_{i t}$ and $K_{i t}$ are the labour, materials and the capital inputs and $A_{i t}$ is the productivity of firm $i$ at time $t$. The constant returns to scale assumption could bias upwardly (downwardly) the estimated levels (changes) in the markup. For a discussion, see Konings et al. (2005a).

Under imperfect competition (see Hall (1988), the output growth rate of the relevant variables can be expressed as:

$$
y_{i t}=R_{i t}\left(s_{i t}^{L} \cdot l_{i t}+s_{i t}^{M} \cdot m_{i t}+s_{i t}^{K} \cdot k_{i t}\right)+\theta_{i t}
$$

where $R_{i t}$ is the ratio between price and marginal cost of firm $i$ and time $t$. $y_{i t}, l_{i t}, m_{i t}$ and $k_{i t}$ are the growth rate of output, labour, materials and capital, respectively. $s_{i t}^{J}$ is the input cost share of factor $J$ in sales (or total value of production), namely

$$
s_{i t}^{J}=\frac{P_{i t}^{J} \cdot J_{i t}}{P_{i t} \cdot x_{i t}}, J=L, M, K .
$$

where $P_{i t}^{j}$ and $P_{i t}$ are the prices of inputs, labour, material and physical capital, and output, respectively. Finally, $\theta_{i t}$ is the growth of productivity.

Equation (64) can be rewritten after some algebra to decompose the Solow residual $\left(S R_{i t}\right)$ into two terms:

$$
S R_{i t}=y_{i t}-s_{i t}^{L} \cdot l_{i t}-s_{i t}^{M} \cdot m_{i t}-\left(1-s_{i t}^{L}-s_{i t}^{M}\right) \cdot k_{i t}=\mu_{i t}\left(y_{i t}-k_{i t}\right)+\left(1-\mu_{i t}\right) \theta_{i t}
$$

where $\mu_{i t}$ is the price marginal cost markup as defined in the main text.

The problem with the estimation of $\mu_{i t}$ is the correlation with the inputs and the unobservable growth of the productivity. Previous empirical research has used Equations (64) or (66) to estimate markups by using instrumental variables but some times is difficult to find exogenous instruments (see, for example, Olley 
and Pakes (1996) and Levishon and Petrin (2003)). Roeger (1995) proposes using the price-based (or dual) Solow residual or the dual Solow residual to deal with this problem. Specifically, using the cost minimization problem and also imposing constant returns to scale, Roeger proposes decomposing the dual Solow residual (DSR) as in equation (66):

$D S R_{i t}=s_{i t}^{L} \cdot p_{i t}^{L}+s_{i t}^{M} \cdot p_{i t}^{M}+\left(1-s_{i t}^{L}-s_{i t}^{M}\right) p_{i t}^{K}-p_{i t}=-\mu_{i t}\left(p_{i t}-p_{i l}^{K}\right)+\left(1-\mu_{i t}\right) \theta_{i t}$

where $p_{i t}^{L}, p_{i t}^{M}, p_{i t}^{K}$ and $p_{i t}$ are the growth rate of the wage, price of intermediates inputs (or materials), the rental price of capital and the output price, respectively.

Subtracting equation (67) from equation (66), we obtain that

$$
\begin{aligned}
S R_{i t}-D S R_{i t} & =\left(y_{i t}+p_{i t}\right)-s_{i t}^{L}\left(l_{i t}+p_{i t}^{L}\right)-s_{i t}^{M}\left(m_{i t}+p_{i t}^{M}\right)-\left(1-s_{i t}^{L}-s_{i t}^{M}\right)\left(k_{i t}+p_{i t}^{K}\right) \\
& =\mu_{i t}\left(y_{i t}+p_{i t}-k_{i t}-p_{i t}^{K}\right)
\end{aligned}
$$

In equation (68) the term which refers to the growth of productivity is eliminated and the problem of simultaneity disappears. In this sense, the Lerner index can be estimated consistently. To simplify notation, we denote the left-hand side in equation (68) as $d x_{i t}$ which can be interpreted as the difference between the growth rate of sales (nominal production) sales and a weighted average of the growth rate of the factors cost weighted by their respective share in sales. We denote the term in brackets on the right-hand side of the equation (68) as $d Z_{i t}$, which can be interpreted as the growth rate of sales per value of capital. Then, the equation to be estimated is:

$$
d x_{i t}=\mu d Z_{i t}+u_{i t}
$$

Different approaches can be followed to estimate Equation (69). Firstly, it can be estimated using panel data and obtaining an average markup of the economy (or the industries considered). This is the approach followed by Konings et al. (2005a and 2005b). Secondly, the availability of a long time period for each firm allows us to estimate individual markups. We are going to use this last one.

\subsection{Data}

Estimations are carried out with an unbalanced panel of Spanish manufacturing firms for the period 1990-2005. The variables were obtained from the Encuesta 
Sobre Estrategias Empresariales (ESEE), a survey that was sponsored by the Ministry of Industry and carried out by the Fundación SEPI. The sampling scheme of this survey is conducted for each manufacturing NACE class (twodigit) level. Companies employing between 10 and 200 employees are chosen by a random sampling scheme and the rate of participation is around $4 \%$. For firms employing more than 200 employees, the rate of participation is about $60 \%$.

The set of variables required to estimate equation (69) are sales $\left(y_{i t} p_{i t}\right)$, nominal labour cost $\left(l_{i t} p_{i t}^{L}\right)$-where $l_{i t}$ is the number of hours effectively worked and $p_{i t}^{L}$ refers to labour costs per employee and hour-, nominal value of intermediate consumption $\left(m_{i t} p_{i t}^{M}\right)$-where $m_{i t}$ is the intermediate consumption and $p_{i t}^{M}$ is a Paasche price index weighting the price variations of raw materials, energy and services purchased-, and the nominal value of capital services $\left(k_{i t} p_{i t}^{K}\right)$.

Hours effectively worked are measured as the sum of the normal working time and overtime minus the non-worked hours, while intermediate consumption is defined as the sum of purchases and external services, minus the variation in the stock of purchases. For capital, we use the net stock of capital for equipment in real terms. It is calculated by using the perpetual inventory formula:

$$
K_{i t}=\left(1-\delta_{i t}\right) K_{i t-1} \frac{P_{i t}^{E}}{P_{i t-1}^{E}}+I_{i t}
$$

where $P_{i t-1}^{E}$ is the price index for equipment, $\delta_{i t}$ is the depreciation rate, and $I_{i t}$ is the investment in equipment. The rental price of capital is calculated as the long-run debt interest rate paid by the firm minus the rate of change in capital goods for the equipment price index plus equipment good depreciation, multiplied by the investment good price index, $P_{i t}^{K}=P_{t}^{E}\left(i_{i t}-\pi_{i t}^{E}+\delta_{i t}\right)$.

\subsection{Results}

Firstly, we began with the standard methodology using panel data. In Table A1, we present the estimation of equation (69) by pooled OLS. We have also run regressions with fixed effects but the null hypothesis that all fixed effects

are equal to zero is not rejected. All of them are carried out by an unbalanced panel of manufacturing firms during the period 1990-2005.

In Column 1 we present the estimation for our sample observations with enough data to build the variables. As can bee seen, the average markups is 0.169 , although there is quite a lot of heterogeneity across industries. 
To test some of the equations of the main text we will need information about the market share of the firm and other variables referring to the real data. Although the ESSE is not a census for the manufacturing firms - only firms with more than 10 employees are surveyed-, it is possible to use the sampling fractions to weight our sample observations. The sampling scheme was conducted for each manufacturing NACE class (two-digit) level and five size categories $^{11}$. The product of 20 sectors and 5 size classes defines the dimension of the weighting matrix, which has a total number of 90 sampling fractions. We have applied the weighting fractions of 2005 to uprate the observations of the firms.

The estimation for this sample is presented in Column 4. As can be seen, the results are quite similar to those presented with our sample.

The dependent variables of the equations of the main text are the Index Lerner. Thus, we need some estimation of the individual markups. As was previously stated, the availability of a sufficient time period for each firm allows us to estimate individual markups although the limitation of this approach is that we will only have one observation for each firm.

For this reason, and secondly, we estimate equation (69) by OLS for 947 firms with more than nine observations. That is:

$$
d x_{t}=\mu_{i} d Z_{t}+u_{t} \quad t>9 \cdots 15
$$

The average markup for these firms is 0.190 . It is quite similar to the one obtained by the standard approach and presented in the last row of Table A1. Almost $10 \%$ of the sample presents negative markups. When these firms are not considered, the average markup increases to 0.224 . Figure 1 presents the distribution of these markups for all firms. As can be seen, the dispersion is large and the distribution is slightly skewed, with a large proportion of firms on the right tail.

Table A2 below presents the average of the estimated individual markups for 20 manufacturing sectors. The average of estimated Lerner index ranges from 0.088 to 0.265 , when all, positive and negative markups are considered.

Due to the fact that we have a small number of observations in some sectors, for the estimation of the equation of the main test, we aggregate some sectors: specifically, Food, Tobacco and Beverages, Timber and Paper, Office Machinery

\footnotetext{
${ }^{11}$ See Segura et alia (1992) for the details.
} 
and Electric Materials and Accessories, Vehicles and Motors and Other Transport Equipment, and Leather, Fur and Footwear and Miscellaneous. 
Table A1. Pooled OLS estimations

\begin{tabular}{lrrrrr} 
& \multicolumn{3}{c}{$\begin{array}{c}\text { Sample observations } \\
(1990-2005)\end{array}$} & \multicolumn{2}{c}{ Uprating the observations } \\
\cline { 2 - 6 } & $0.108(8.6)$ & 77 & 603 & $0.106(44.9)$ & 17122 \\
\hline Meat related products & $0.133(15.6)$ & 252 & 1971 & $0.130(74.5)$ & 48193 \\
\hline Food and tobacco & $0.189(9.1)$ & 55 & 395 & $0.138(19.8)$ & 4662 \\
\hline Beverages & $0.170(17.1)$ & 256 & 1851 & $0.193(81.5)$ & 33377 \\
\hline Textiles and clothing & $0.177(8.5)$ & 83 & 467 & $0.190(44.2)$ & 11008 \\
\hline Leather, fur and footwear & $0.144(8.5)$ & 77 & 516 & $0.158(57.4)$ & 21197 \\
\hline Timber & $0.201(13.5)$ & 68 & 526 & $0.173(48.0)$ & 7820 \\
\hline Paper & $0.187(15.8)$ & 141 & 1029 & $0.194(97.5)$ & 31940 \\
\hline Printing and Publishing & $0.164(16.8)$ & 179 & 1379 & $0.146(51.9)$ & 20912 \\
\hline Chemicals & $0.130(11.6)$ & 141 & 1031 & $0.129(48.1)$ & 19587 \\
\hline Plastic and rubber products & $0.219(19.7)$ & 172 & 1340 & $0.230(90.4)$ & 29477 \\
\hline Non-mineral products & $0.166(12.6)$ & 77 & 653 & $0.169(46.9)$ & 9040 \\
\hline Basic metal products & $0.192(21.2)$ & 261 & 1835 & $0.207(118.8)$ & 51330 \\
\hline Fabricated metal products & $0.196(19.0)$ & 183 & 1407 & $0.221(90.9)$ & 27988 \\
\hline Industrial and agricultural equipment & $0.129(5.0)$ & 53 & 286 & $0.107(15.3)$ & 5040 \\
\hline Office mach. data processing and similar & $0.168(14.8)$ & 169 & 1211 & $0.194(60.7)$ & 16752 \\
\hline Electric materials and accessories & $0.159(14.7)$ & 125 & 980 & $0.163(42.1)$ & 9327 \\
\hline Vehicles and motors & $0.164(7.6)$ & 50 & 371 & $0.147(19.1)$ & 3569 \\
\hline Other transport equipment & $0.162(12.0)$ & 134 & 949 & $0.166(63.8)$ & 26593 \\
\hline Furniture & $0.187(9.6)$ & 59 & 441 & $0.190(49.3)$ & 11786 \\
\hline Miscellaneous & $0.169(9.6)$ & 2612 & 19241 & $0.177(281.9)$ & 406720 \\
\hline All firms & & & & \\
\hline \hline
\end{tabular}




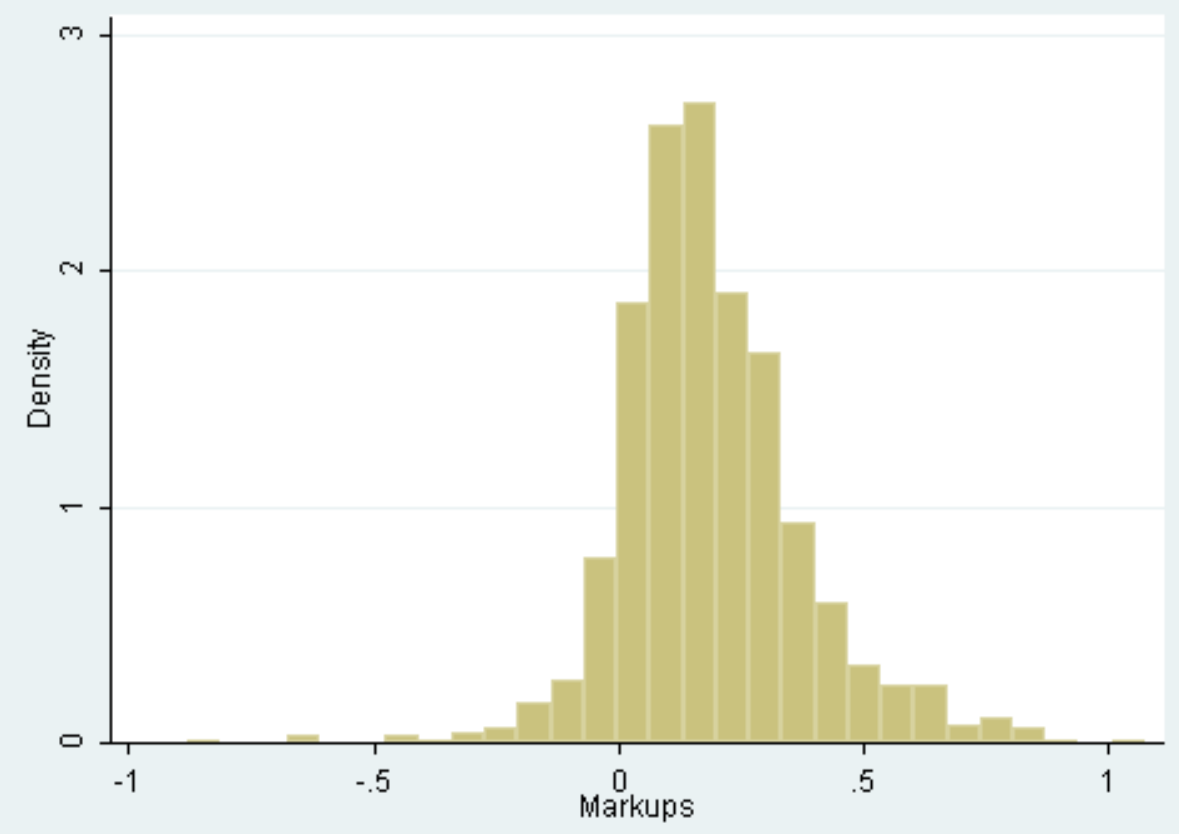

Figure 1. Markups distribution 
Table A2. Average Individual Mark-ups by sectors

\begin{tabular}{lcccccr}
\cline { 2 - 7 } & \multicolumn{3}{c}{ Positive \& negative } & \multicolumn{2}{c}{ Positive markups } \\
\hline & Mean & S.D & Firms & Mean & S.D. & Firms \\
\hline Meat related products & 0.088 & 0.139 & 33 & 0.123 & 0.134 & 26 \\
\hline Food and tobacco & 0.144 & 0.156 & 106 & 0.183 & 0.130 & 90 \\
\hline Beverages & 0.203 & 0.202 & 19 & 0.258 & 0.165 & 16 \\
\hline Textiles and clothing & 0.169 & 0.230 & 95 & 0.225 & 0.162 & 83 \\
\hline Leather, fur and footwear & 0.227 & 0.178 & 20 & 0.255 & 0.165 & 18 \\
\hline Timber & 0.201 & 0.165 & 23 & 0.212 & 0.161 & 22 \\
\hline Paper & 0.209 & 0.194 & 27 & 0.226 & 0.191 & 25 \\
\hline Printing and Publishing & 0.265 & 0.195 & 48 & 0.265 & 0.195 & 48 \\
\hline Chemicals & 0.198 & 0.171 & 70 & 0.214 & 0.162 & 66 \\
\hline Plastic and rubber products & 0.139 & 0.195 & 43 & 0.177 & 0.127 & 40 \\
\hline Non-mineral products & 0.244 & 0.219 & 72 & 0.286 & 0.191 & 64 \\
\hline Basic metal products & 0.177 & 0.137 & 37 & 0.184 & 0.132 & 36 \\
\hline Fabricated metal products & 0.201 & 0.174 & 81 & 0.232 & 0.154 & 73 \\
\hline Ind. and agric. equipment & 0.199 & 0.223 & 74 & 0.253 & 0.179 & 64 \\
\hline Office mach. and similar & 0.257 & 0.257 & 10 & 0.328 & 0.237 & 8 \\
\hline Electric materials and accessories & 0.219 & 0.187 & 57 & 0.253 & 0.165 & 51 \\
\hline Vehicles \& motors & 0.181 & 0.138 & 52 & 0.190 & 0.134 & 50 \\
\hline Other transport equipment & 0.149 & 0.253 & 20 & 0.220 & 0.187 & 17 \\
\hline Furniture & 0.194 & 0.184 & 38 & 0.230 & 0.157 & 34 \\
\hline Miscellaneous & 0.233 & 0.185 & 22 & 0.245 & 0.182 & 21 \\
\hline All firms & 0.191 & 0.192 & 947 & 0.224 & 0.164 & 852 \\
\hline \hline
\end{tabular}




\subsection{Appendix II: Definitions of the variables}

Capital stock of equipment goods: Net stock of capital for equipment goods in real terms. This is calculated by using the perpetual inventory formula: $K_{t}=(1-d) K_{t-1}\left(P_{t} / P_{t-1}\right)+I_{t}$, where $P$ is the price index for equipment, $d$ is the depreciation rate, and $I$ is the investment in equipment.

Effective hours of work: Normal hours plus overtime hours minus lost hours.

Intermediate consumption: Raw material purchases, energy and fuel costs and other external services.

Market share $\frac{p_{i} x_{i}}{\sum_{i=1}^{n} p_{i} x_{i}}$ : The ratio of the nominal output of the firm over the total nominal of the sector output for each year. The denominator is calculated uprating the observations by the sampling fractions in 2005 .

Output $\left(x_{i}\right)$ : Nominal output -Sales plus stock variation- is deflated using Paasche-type firm individual indices, constructed starting from the price changes in output reported by firms (Price).

Price $\left(p_{i}\right)$ : The surveyed firms give annual information about markets served (up to five), identifying their relative importance (in percentage) in total sales of the firm. This information allows us to calculate a price Paasche-type index for all markets and for each market, using the proportions with respect to total sales as weighting. 
Table 1a. OLS cross-section estimation of Equation (20)

\begin{tabular}{|c|c|c|c|c|}
\hline & \multicolumn{4}{|c|}{ Positive \& negative markups } \\
\hline & $a$ & $b$ & Firms & $R^{2}$ \\
\hline \multirow[t]{2}{*}{ Meat related products } & $0.071^{* * *}$ & 4.7 & 33 & 0.01 \\
\hline & $(0.028)$ & $(4.1)$ & & \\
\hline \multirow[t]{2}{*}{ Food, tobacco and beverages } & $0.160^{* * *}$ & -9.7 & 125 & 0.0 \\
\hline & $(0.016)$ & $(10.6)$ & & \\
\hline \multirow[t]{2}{*}{ Textiles and clothing } & $0.171^{* * *}$ & -1.3 & 95 & 0.0 \\
\hline & $(0.028)$ & $(10.2)$ & & \\
\hline \multirow[t]{2}{*}{ Timber and paper } & $0.168^{* * *}$ & $13.9^{* *}$ & 50 & 0.11 \\
\hline & $(0.028)$ & $(5.2)$ & & \\
\hline \multirow[t]{2}{*}{ Printing and Publishing } & $0.276^{* * *}$ & -4.1 & 48 & 0.0 \\
\hline & $(0.031)$ & $(4.4)$ & & \\
\hline \multirow[t]{2}{*}{ Chemicals } & $0.231^{* * *}$ & $-24.0^{* *}$ & 70 & 0.07 \\
\hline & $(0.024)$ & $(9.5)$ & & \\
\hline \multirow[t]{2}{*}{ Plastic and rubber products } & $0.142^{* * *}$ & -1.5 & 43 & 0.0 \\
\hline & $(0.035)$ & $(7.9)$ & & \\
\hline \multirow[t]{2}{*}{ Non-mineral products } & $0.253^{* * *}$ & -4.6 & 72 & 0.0 \\
\hline & $(0.030)$ & $(7.9)$ & & \\
\hline \multirow[t]{2}{*}{ Basic metal products } & $0.171^{* * *}$ & 1.1 & 37 & 0.0 \\
\hline & $(0.025)$ & $(2.0)$ & & \\
\hline \multirow[t]{2}{*}{ Fabricated metal products } & $0.213^{* * *}$ & -13.1 & 81 & 0.0 \\
\hline & $(0.022)$ & $(11.2)$ & & \\
\hline \multirow[t]{2}{*}{ Ind. and agric. equipment } & $0.215^{* * *}$ & -5.8 & 74 & 0.01 \\
\hline & $(0.029)$ & $(4.6)$ & & \\
\hline \multirow[t]{2}{*}{ Office mach. and Electric mat. } & $0.234^{* * *}$ & -5.2 & 67 & 0.0 \\
\hline & $(0.028)$ & $(7.8)$ & & \\
\hline \multirow[t]{2}{*}{ Vehicles and transport equip. } & $0.172^{* * *}$ & 0.1 & 72 & 0.0 \\
\hline & $(0.022)$ & $(4.5)$ & & \\
\hline \multirow[t]{2}{*}{ Furniture } & $0.174^{* * *}$ & 7.4 & 38 & 0.02 \\
\hline & $(0.033)$ & $(5.7)$ & & \\
\hline \multirow[t]{2}{*}{ Leather, fur, footwear and Miscellaneous } & $0.213^{* * *}$ & 14.4 & 42 & 0.0 \\
\hline & $(0.032)$ & $(13.5)$ & & \\
\hline \multirow[t]{2}{*}{ All firms } & $0.190^{* * *}$ & 0.04 & 947 & 0.0 \\
\hline & $(0.007)$ & $(1.1)$ & & \\
\hline
\end{tabular}


Table 1b. OLS cross-section estimation of Equation (20)

\begin{tabular}{|c|c|c|c|c|}
\hline & \multicolumn{4}{|c|}{ Positive markups } \\
\hline & $a$ & $b$ & Firms & $R^{2}$ \\
\hline \multirow[t]{2}{*}{ Meat related products } & $0.109^{* * *}$ & 3.8 & 26 & 0.00 \\
\hline & $(0.030)$ & $(4.2)$ & & \\
\hline \multirow[t]{2}{*}{ Food, tobacco and beverages } & $0.205^{* * *}$ & -15.1 & 106 & 0.01 \\
\hline & $(0.016)$ & $(11.8)$ & & \\
\hline \multirow[t]{2}{*}{ Textiles \& clothing } & $0.228^{* * *}$ & -1.5 & 83 & 0.0 \\
\hline & $(0.021)$ & $(7.4)$ & & \\
\hline \multirow[t]{2}{*}{ Timber \& paper } & $0.178^{* * *}$ & $15.9 * * *$ & 47 & 0.16 \\
\hline & $(0.027)$ & $(5.2)$ & & \\
\hline \multirow[t]{2}{*}{ Printing \& Publishing } & $0.256^{* * *}$ & -3.0 & 47 & 0.0 \\
\hline & $(0.025)$ & $(3.5)$ & & \\
\hline \multirow[t]{2}{*}{ Chemicals } & $0.243^{* * *}$ & $-21.3^{* *}$ & 66 & 0.06 \\
\hline & $(0.023)$ & $(9.5)$ & & \\
\hline \multirow[t]{2}{*}{ Plastic \& rubber products } & $0.187^{* * *}$ & -4.6 & 40 & 0.0 \\
\hline & $(0.024)$ & $(5.2)$ & & \\
\hline \multirow[t]{2}{*}{ Non-mineral products } & $0.305^{* * *}$ & -9.3 & 64 & 0.01 \\
\hline & $(0.028)$ & $(6.9)$ & & \\
\hline \multirow[t]{2}{*}{ Basic metal products } & $0.178^{* * *}$ & 1.1 & 36 & 0.0 \\
\hline & $(0.025)$ & $(2.0)$ & & \\
\hline \multirow[t]{2}{*}{ Fabricated metal products } & $0.247^{* * *}$ & $-16.6^{*}$ & 73 & 0.02 \\
\hline & $(0.020)$ & $(9.9)$ & & \\
\hline \multirow[t]{2}{*}{ Ind. and agric. equipment } & $0.271^{* * *}$ & -6.3 & 64 & 0.03 \\
\hline & $(0.025)$ & $(3.8)$ & & \\
\hline \multirow[t]{2}{*}{ Office mach. \& Electric mat. } & $0.280^{* * *}$ & -8.1 & 59 & 0.01 \\
\hline & $(0.027)$ & $(7.0)$ & & \\
\hline \multirow[t]{2}{*}{ Vehicles \& transport equip. } & $0.197^{* * *}$ & 0.0 & 67 & 0.0 \\
\hline & $(0.019)$ & $(3.8)$ & & \\
\hline \multirow[t]{2}{*}{ Furniture } & $0.191^{* * *}$ & $19.3^{* * *}$ & 34 & 0.33 \\
\hline & $(0.024)$ & $(4.7)$ & & \\
\hline \multirow[t]{2}{*}{ Leather, fur \& Miscellaneous } & $0.237^{* * *}$ & 9.9 & 39 & 0.0 \\
\hline & $(0.032)$ & $(13.1)$ & & \\
\hline \multirow[t]{2}{*}{ All firms } & $0.223^{* * *}$ & 0.07 & 851 & 0.0 \\
\hline & $(0.006)$ & $(1.0)$ & & \\
\hline
\end{tabular}


Table 2. OLS cross-section estimation of Equation (26)

\begin{tabular}{|c|c|c|c|c|c|c|}
\hline & \multicolumn{6}{|c|}{ Positive and negative markups } \\
\hline & $a$ & $b$ & $d$ & $e$ & Firms & $R^{2}$ \\
\hline \multirow[t]{2}{*}{ Meat related products } & $4.7^{*}$ & 0.005 & 0.001 & $-0.0004^{*}$ & 33 & 0.06 \\
\hline & $(2.5)$ & $(0.197)$ & $(0.001)$ & $(0.0002)$ & & \\
\hline \multirow[t]{2}{*}{ Food, tobacco and beverages } & -0.8 & $0.210^{* *}$ & -0.0002 & 0.000 & 125 & 0.05 \\
\hline & $(0.6)$ & $(0.109)$ & $(0.0003)$ & $(0.000)$ & & \\
\hline \multirow[t]{2}{*}{ Textiles and clothing } & -0.8 & $0.245^{*}$ & -0.000 & 0.0001 & 95 & 0.00 \\
\hline & $(1.5)$ & $(0.141)$ & $(0.001)$ & $(0.0001)$ & & \\
\hline \multirow[t]{2}{*}{ Timber and paper } & -0.2 & 0.141 & $0.001^{* *}$ & 0.000 & 50 & 0.08 \\
\hline & $(0.4)$ & $(0.175)$ & $(0.001)$ & $(0.000)$ & & \\
\hline \multirow[t]{2}{*}{ Printing and Publishing } & 0.6 & 0.118 & -0.001 & -0.000 & 48 & 0.00 \\
\hline & $(1.1)$ & $(0.131)$ & $(0.001)$ & $(0.0001)$ & & \\
\hline \multirow[t]{2}{*}{ Chemicals } & 0.2 & $0.293^{* *}$ & $-0.001^{* *}$ & -0.000 & 70 & 0.14 \\
\hline & $(0.7)$ & $(0.125)$ & $(0.0003)$ & $(0.000)$ & & \\
\hline \multirow[t]{2}{*}{ Plastic and rubber products } & -0.4 & 0.154 & -0.0001 & 0.000 & 43 & 0.00 \\
\hline & $(0.5)$ & $(0.265)$ & $(0.001)$ & $(0.000)$ & & \\
\hline \multirow[t]{2}{*}{ Non-mineral products } & 1.1 & 0.002 & -0.0003 & -0.0001 & 72 & 0.00 \\
\hline & $(0.6)$ & $(0.164)$ & $(0.001)$ & $(0.000)$ & & \\
\hline \multirow[t]{2}{*}{ Basic metal products } & 0.6 & $0.250^{*}$ & -0.000 & -0.000 & 37 & 0.05 \\
\hline & $(0.6)$ & $(0.133)$ & $(0.000)$ & $(0.000)$ & & \\
\hline \multirow[t]{2}{*}{ Fabricated metal products } & -0.1 & $0.376^{* *}$ & -0.001 & -0.000 & 81 & 0.06 \\
\hline & $(0.4)$ & $(0.156)$ & $(0.001)$ & $(0.000)$ & & \\
\hline \multirow[t]{2}{*}{ Industrial and agricultural equipment } & 0.3 & $0.359^{*}$ & -0.0004 & -0.000 & 74 & 0.02 \\
\hline & $(0.9)$ & $(0.206)$ & $(0.0004)$ & $(0.0001)$ & & \\
\hline \multirow[t]{2}{*}{ Office mach. and Electric materials } & -0.7 & $0.439^{* *}$ & -0.000 & 0.000 & 67 & 0.06 \\
\hline & $(0.8)$ & $(0.187)$ & $(0.0003)$ & $(0.0001)$ & & \\
\hline \multirow[t]{2}{*}{ Vehicles and transport equipment } & -0.4 & $0.299^{* *}$ & -0.000 & 0.000 & 72 & 0.01 \\
\hline & $(0.4)$ & $(0.169)$ & $(0.0001)$ & $(0.000)$ & & \\
\hline \multirow[t]{2}{*}{ Furniture } & 0.2 & $0.563^{* *}$ & 0.002 & -0.0002 & 38 & 0.11 \\
\hline & $(1.1)$ & $(0.219)$ & $(0.001)$ & $(0.0003)$ & & \\
\hline \multirow[t]{2}{*}{ Leather, fur, footwear and Misc. } & -1.8 & 0.165 & 0.003 & 0.0003 & 42 & 0.00 \\
\hline & $(2.9)$ & $(0.257)$ & $(0.003)$ & $(0.0004)$ & & \\
\hline \multirow[t]{2}{*}{ All firms } & -0.02 & $0.221^{* * *}$ & -0.0001 & $-0.0000^{*}$ & 947 & 0.04 \\
\hline & $(0.01)$ & $(0.039)$ & $(0.0001)$ & $(0.0000)$ & & \\
\hline
\end{tabular}


Table 3. OLS cross-section estimation of Equation (32)

\begin{tabular}{|c|c|c|c|c|c|}
\hline & \multicolumn{5}{|c|}{ Positive markups } \\
\hline & $a$ & $b$ & Firms & $\rho$ & $R^{2}$ \\
\hline \multirow[t]{2}{*}{ Meat related products } & $27.2^{* * *}$ & -6.7 & 26 & 0.963 & 0.00 \\
\hline & $(8.1)$ & $(9.2)$ & & & \\
\hline \multirow[t]{2}{*}{ Food, tobacco and beverages } & $14.1^{* * *}$ & -2.6 & 106 & 0.929 & 0.00 \\
\hline & $(4.2)$ & $(3.3)$ & & & \\
\hline \multirow[t]{2}{*}{ Textiles and clothing } & $10.7^{* * *}$ & -1.1 & 83 & 0.907 & 0.00 \\
\hline & $(2.6)$ & $(2.0)$ & & & \\
\hline \multirow[t]{2}{*}{ Timber and paper } & $9.4^{* * *}$ & -1.0 & 47 & 0.893 & 0.00 \\
\hline & $(1.7)$ & $(2.0)$ & & & \\
\hline \multirow[t]{2}{*}{ Printing and Publishing } & $10.4^{* * *}$ & -1.7 & 47 & 0.904 & 0.00 \\
\hline & $(2.9)$ & $(1.9)$ & & & \\
\hline \multirow[t]{2}{*}{ Chemicals } & $11.1^{* * *}$ & 1.8 & 66 & 0.910 & 0.00 \\
\hline & $(2.3)$ & $(4.7)$ & & & \\
\hline \multirow[t]{2}{*}{ Plastic and rubber products } & $12.7^{* * *}$ & -1.5 & 40 & 0.921 & 0.00 \\
\hline & $(3.2)$ & $(4.0)$ & & & \\
\hline \multirow[t]{2}{*}{ Non-mineral products } & $10.4^{* *}$ & 2.1 & 64 & 0.904 & 0.01 \\
\hline & $(4.3)$ & $(5.1)$ & & & \\
\hline \multirow[t]{2}{*}{ Basic metal products } & $13.2^{* * *}$ & -4.1 & 36 & 0.924 & 0.00 \\
\hline & $(3.5)$ & $(13.4)$ & & & \\
\hline \multirow[t]{2}{*}{ Fabricated metal products } & $9.7^{* * *}$ & -2.8 & 73 & 0.896 & 0.02 \\
\hline & $(1.5)$ & $(1.8)$ & & & \\
\hline \multirow[t]{2}{*}{ Industrial and agricultural equipment } & $9.6^{* * *}$ & -2.4 & 64 & 0.895 & 0.01 \\
\hline & $(1.8)$ & $(2.1)$ & & & \\
\hline \multirow[t]{2}{*}{ Office mach. and Electric materials } & $6.0^{* * *}$ & $3.1^{* *}$ & 59 & 0.833 & 0.04 \\
\hline & $(1.3)$ & $(1.6)$ & & & \\
\hline \multirow[t]{2}{*}{ Vehicles and transport equipment } & 19.7 & $259.6^{* *}$ & 67 & 0.949 & 0.03 \\
\hline & $(49.7)$ & $(149.7)$ & & & \\
\hline \multirow[t]{2}{*}{ Furniture } & $5.0^{* *}$ & 3.3 & 34 & 0.800 & 0.04 \\
\hline & $(2.5)$ & $(2.2)$ & & & \\
\hline \multirow[t]{2}{*}{ Leather, fur, footwear and Misc. } & $7.7^{* * *}$ & 0.7 & 39 & 0.870 & 0.00 \\
\hline & $(2.3)$ & $(2.1)$ & & & \\
\hline \multirow[t]{2}{*}{ All firms } & $14.0^{* * *}$ & -0.4 & 851 & 0.929 & 0.00 \\
\hline & $(4.4)$ & $(4.5)$ & & & \\
\hline
\end{tabular}


Table 4a. OLS cross-section Estimation of $\rho$ and Equation (43)

\begin{tabular}{|c|c|c|c|c|}
\hline & \multicolumn{4}{|c|}{ Positive and negative markups } \\
\hline & Estimated $\rho$ & $a$ & Firms & $R^{2}$ \\
\hline \multirow[t]{2}{*}{ Meat related products } & 0.969 & $0.0009^{* *}$ & 33 & 0.10 \\
\hline & & $(0.0004)$ & & \\
\hline \multirow[t]{2}{*}{ Food, tobacco and beverages } & 0.958 & $0.0006^{* *}$ & 125 & 0.03 \\
\hline & & $(0.0003)$ & & \\
\hline \multirow[t]{2}{*}{ Textiles and clothing } & 0.972 & $0.002^{* *}$ & 95 & 0.04 \\
\hline & & $(0.001)$ & & \\
\hline \multirow[t]{2}{*}{ Timber and paper } & 0.984 & $0.003^{* * *}$ & 50 & 0.35 \\
\hline & & $(0.001)$ & & \\
\hline \multirow[t]{2}{*}{ Printing and Publishing } & 0.967 & $0.002^{*}$ & 48 & 0.04 \\
\hline & & $(0.001)$ & & \\
\hline \multirow[t]{2}{*}{ Chemicals } & 0.971 & $0.0006^{*}$ & 70 & 0.03 \\
\hline & & $(0.0003)$ & & \\
\hline \multirow[t]{2}{*}{ Plastic and rubber products } & 0.984 & $0.001^{*}$ & 43 & 0.04 \\
\hline & & $(0.0007)$ & & \\
\hline \multirow[t]{2}{*}{ Non-mineral products } & 0.994 & $0.002^{* * *}$ & 72 & 0.09 \\
\hline & & $(0.0006)$ & & \\
\hline \multirow[t]{2}{*}{ Basic metal products } & 0.995 & $0.0004^{* *}$ & 36 & 0.14 \\
\hline & & $(0.0002)$ & & \\
\hline \multirow[t]{2}{*}{ Fabricated metal products } & 0.959 & $0.002^{* *}$ & 81 & 0.05 \\
\hline & & $(0.001)$ & & \\
\hline \multirow[t]{2}{*}{ Industrial and agricultural equipment } & 0.965 & 0.0006 & 74 & 0.02 \\
\hline & & $(0.0004)$ & & \\
\hline \multirow[t]{2}{*}{ Office mach. and Electric materials } & 0.970 & $0.001^{* * *}$ & 67 & 0.09 \\
\hline & & $(0.0004)$ & & \\
\hline \multirow[t]{2}{*}{ Vehicles and transport equipment } & 0.979 & $0.0002^{* *}$ & 72 & 0.04 \\
\hline & & $(0.0001)$ & & \\
\hline \multirow[t]{2}{*}{ Furniture } & 0.955 & $0.004^{* *}$ & 38 & 0.13 \\
\hline & & $(0.002)$ & & \\
\hline \multirow[t]{2}{*}{ Leather, fur, footwear and Misc. } & 0.957 & $0.010^{* * *}$ & 42 & 0.20 \\
\hline & & $(0.003)$ & & \\
\hline \multirow[t]{2}{*}{ All firms } & 0.969 & $0.0005^{* * *}$ & 947 & 0.04 \\
\hline & & $(0.0001)$ & & \\
\hline
\end{tabular}


Table 4b. OLS cross-section estimation of $\rho$ and Equation (43)

\begin{tabular}{|c|c|c|c|c|}
\hline & \multicolumn{4}{|c|}{ Positive markups } \\
\hline & Estimated $\rho$ & $a$ & Firms & $R^{2}$ \\
\hline \multirow[t]{2}{*}{ Meat related products } & 0.973 & $0.001^{* *}$ & 23 & 0.16 \\
\hline & & $(0.0005)$ & & \\
\hline \multirow[t]{2}{*}{ Food, tobacco and beverages } & 0.958 & $0.001^{* * *}$ & 101 & 0.10 \\
\hline & & $(0.0004)$ & & \\
\hline \multirow[t]{2}{*}{ Textiles and clothing } & 0.972 & $0.004^{* * *}$ & 81 & 0.16 \\
\hline & & $(0.001)$ & & \\
\hline \multirow[t]{2}{*}{ Timber and paper } & 0.985 & $0.003^{* * *}$ & 47 & 0.38 \\
\hline & & $(0.001)$ & & \\
\hline \multirow[t]{2}{*}{ Printing and Publishing } & 0.964 & $0.002^{* *}$ & 45 & 0.06 \\
\hline & & $(0.001)$ & & \\
\hline \multirow[t]{2}{*}{ Chemicals } & 0.966 & $0.001^{* * *}$ & 59 & 0.12 \\
\hline & & $(0.0005)$ & & \\
\hline \multirow[t]{2}{*}{ Plastic and rubber products } & 0.982 & $0.001^{*}$ & 39 & 0.09 \\
\hline & & $(0.0006)$ & & \\
\hline \multirow[t]{2}{*}{ Non-mineral products } & 0.997 & $0.002^{* * *}$ & 64 & 0.10 \\
\hline & & $(0.0007)$ & & \\
\hline \multirow[t]{2}{*}{ Basic metal products } & 1.0 & $0.0004^{* *}$ & 35 & 0.15 \\
\hline & & $(0.0002)$ & & \\
\hline \multirow[t]{2}{*}{ Fabricated metal products } & 0.959 & $0.003^{* *}$ & 69 & 0.07 \\
\hline & & $(0.001)$ & & \\
\hline \multirow[t]{2}{*}{ Industrial and agricultural equipment } & 0.967 & $0.0009 *$ & 62 & 0.04 \\
\hline & & $(0.0005)$ & & \\
\hline \multirow[t]{2}{*}{ Office mach. and Electric materials } & 0.969 & $0.001^{* *}$ & 57 & 0.10 \\
\hline & & $(0.0004)$ & & \\
\hline \multirow[t]{2}{*}{ Vehicles and transport equipment } & 0.976 & $0.0002^{* *}$ & 66 & 0.06 \\
\hline & & $(0.0001)$ & & \\
\hline \multirow[t]{2}{*}{ Furniture } & 0.953 & $0.008^{* * *}$ & 33 & 0.40 \\
\hline & & $(0.002)$ & & \\
\hline \multirow[t]{2}{*}{ Leather, fur, footwear and Misc. } & 0.953 & $0.010^{* * *}$ & 37 & 0.20 \\
\hline & & $(0.003)$ & & \\
\hline \multirow[t]{2}{*}{ All firms } & 0.969 & $0.0006^{* * *}$ & 812 & 0.06 \\
\hline & & $(0.0001)$ & & \\
\hline
\end{tabular}


Table 5. OLS cross-section estimation of Equation (45)

\begin{tabular}{|c|c|c|c|c|c|c|}
\hline & \multicolumn{3}{|c|}{ Positive and negative markups } & \multicolumn{3}{|c|}{ Positive markups } \\
\hline & $a$ & Firms & $R^{2}$ & $a$ & Firms & $R^{2}$ \\
\hline \multirow[t]{2}{*}{ Meat related products } & $0.001^{* *}$ & 33 & 0.16 & $0.001^{* *}$ & 26 & 0.19 \\
\hline & $(0.0004)$ & & & $(0.0005)$ & & \\
\hline \multirow[t]{2}{*}{ Food, tobacco and beverages } & $0.001^{* * *}$ & 125 & 0.06 & $0.001^{* * *}$ & 106 & 0.11 \\
\hline & $(0.0002)$ & & & $(0.0003)$ & & \\
\hline \multirow[t]{2}{*}{ Textiles and clothing } & $0.002^{* *}$ & 95 & 0.05 & $0.004^{* * *}$ & 83 & 0.17 \\
\hline & $(0.001)$ & & & $(0.001)$ & & \\
\hline \multirow[t]{2}{*}{ Timber and paper } & $0.003^{* * *}$ & 50 & 0.35 & $0.003^{* * *}$ & 47 & 0.37 \\
\hline & $(0.001)$ & & & $(0.001)$ & & \\
\hline \multirow[t]{2}{*}{ Printing and Publishing } & $0.002^{*}$ & 48 & 0.04 & $0.002^{* *}$ & 47 & 0.06 \\
\hline & $(0.001)$ & & & $(0.001)$ & & \\
\hline \multirow[t]{2}{*}{ Chemicals } & $0.0006^{*}$ & 70 & 0.05 & $0.001^{* *}$ & 66 & 0.07 \\
\hline & $(0.0002)$ & & & $(0.0003)$ & & \\
\hline \multirow[t]{2}{*}{ Plastic and rubber products } & $0.001^{*}$ & 43 & 0.06 & $0.001^{*}$ & 40 & 0.10 \\
\hline & $(0.0006)$ & & & $(0.0006)$ & & \\
\hline \multirow[t]{2}{*}{ Non-mineral products } & $0.002^{* * *}$ & 72 & 0.10 & $0.002^{* * *}$ & 64 & 0.10 \\
\hline & $(0.0006)$ & & & $(0.0006)$ & & \\
\hline \multirow[t]{2}{*}{ Basic metal products } & $0.0004^{* *}$ & 37 & 0.15 & $0.0004^{* *}$ & 36 & 0.15 \\
\hline & $(0.0002)$ & & & $(0.0002)$ & & \\
\hline \multirow[t]{2}{*}{ Fabricated metal products } & $0.002^{* *}$ & 81 & 0.07 & $0.003^{* *}$ & 73 & 0.09 \\
\hline & $(0.001)$ & & & $(0.001)$ & & \\
\hline \multirow[t]{2}{*}{ Industrial and agricultural equipment } & $0.001^{*}$ & 74 & 0.03 & $0.001^{* * *}$ & 64 & 0.05 \\
\hline & $(0.0004)$ & & & $(0.001)$ & & \\
\hline \multirow[t]{2}{*}{ Office mach. and Electric materials } & $0.001^{* * *}$ & 67 & 0.11 & $0.001^{* *}$ & 59 & 0.12 \\
\hline & $(0.0004)$ & & & $(0.0004)$ & & \\
\hline \multirow[t]{2}{*}{ Vehicles and transport equipment } & $0.0002^{* *}$ & 72 & 0.05 & $0.0002^{* *}$ & 67 & 0.06 \\
\hline & $(0.0001)$ & & & $(0.0001)$ & & \\
\hline \multirow[t]{2}{*}{ Furniture } & $0.004^{* * *}$ & 38 & 0.15 & $0.007 * * *$ & 34 & 0.36 \\
\hline & $(0.001)$ & & & $(0.0002)$ & & \\
\hline \multirow[t]{2}{*}{ Leather, fur, footwear and Misc. } & $0.010^{* * *}$ & 42 & 0.22 & $0.010^{* * *}$ & 39 & 0.21 \\
\hline & $(0.003)$ & & & $(0.003)$ & & \\
\hline \multirow[t]{2}{*}{ All firms } & $0.0005^{* * *}$ & 947 & 0.04 & $0.0006^{* * *}$ & 852 & 0.06 \\
\hline & $(0.0001)$ & & & $(0.0001)$ & & \\
\hline
\end{tabular}


Table 6a. OLS cross-section estimation of Equation (62)

\begin{tabular}{|c|c|c|c|c|c|}
\hline & \multicolumn{5}{|c|}{ Positive markups } \\
\hline & $a$ & $b$ & Firms & $>0$ & $R^{2}$ \\
\hline \multirow[t]{2}{*}{ Meat related products } & $0.004^{* *}$ & -0.00001 & 26 & 3 & 0.25 \\
\hline & $(0.001)$ & $(0.0)$ & & & \\
\hline \multirow[t]{2}{*}{ Food, tobacco and beverages } & $0.004^{* * *}$ & $-0.00001^{* * *}$ & 106 & 10 & 0.20 \\
\hline & $(0.001)$ & $(0.0)$ & & & \\
\hline \multirow[t]{2}{*}{ Textiles and clothing } & $0.012^{* * *}$ & $-0.0001 * * *$ & 83 & 9 & 0.26 \\
\hline & $(0.003)$ & $(0.0)$ & & & \\
\hline \multirow[t]{2}{*}{ Timber and paper } & $0.005^{* * *}$ & $-0.00001^{* *}$ & 47 & 2 & 0.41 \\
\hline & $(0.001)$ & $(0.0)$ & & & \\
\hline \multirow[t]{2}{*}{ Printing and Publishing } & $0.006^{* *}$ & -0.00003 & 47 & 3 & 0.09 \\
\hline & $(0.003)$ & $(0.0)$ & & & \\
\hline \multirow[t]{2}{*}{ Chemicals } & $0.003^{* * *}$ & $-0.000^{* * *}$ & 66 & 7 & 0.21 \\
\hline & $(0.001)$ & $(0.0)$ & & & \\
\hline \multirow[t]{2}{*}{ Plastic and rubber products } & $0.004^{* *}$ & $-0.00001^{* *}$ & 40 & 3 & 0.18 \\
\hline & $(0.001)$ & $(0.0)$ & & & \\
\hline \multirow[t]{2}{*}{ Non-mineral products } & $0.006^{* * *}$ & $-0.00002^{* *}$ & 64 & 1 & 0.25 \\
\hline & $(0.001)$ & $(0.0)$ & & & \\
\hline \multirow[t]{2}{*}{ Basic metal products } & $0.002^{* * *}$ & $-0.000^{* * *}$ & 36 & 1 & 0.36 \\
\hline & $(0.000)$ & $(0.0)$ & & & \\
\hline \multirow[t]{2}{*}{ Fabricated metal products } & $0.008^{* * *}$ & $-0.00005^{* * *}$ & 73 & 3 & 0.18 \\
\hline & $(0.002)$ & $(0.00002)$ & & & \\
\hline \multirow[t]{2}{*}{ Industrial and agricultural equipment } & $0.003^{* * *}$ & $-0.000^{* *}$ & 64 & 3 & 0.10 \\
\hline & $(0.001)$ & $(0.0)$ & & & \\
\hline \multirow[t]{2}{*}{ Office mach. and Electric materials } & $0.004^{* * *}$ & $-0.00001^{* *}$ & 59 & 7 & 0.19 \\
\hline & $(0.001)$ & $(0.0)$ & & & \\
\hline \multirow[t]{2}{*}{ Vehicles and transport equipment } & $0.001^{* * *}$ & $-0.0000^{* * *}$ & 67 & 2 & 0.26 \\
\hline & $(0.0003)$ & $(0.0)$ & & & \\
\hline \multirow[t]{2}{*}{ Furniture } & $0.028^{* * *}$ & $-0.0002^{* * *}$ & 34 & 2 & 0.56 \\
\hline & $(0.005)$ & $(0.0001)$ & & & \\
\hline \multirow[t]{2}{*}{ Leather, fur, footwear and Misc. } & $0.023^{* * *}$ & -0.0003 & 39 & 2 & 0.25 \\
\hline & $(0.008)$ & $(0.0002)$ & & & \\
\hline \multirow[t]{2}{*}{ All firms } & $0.002^{* * *}$ & $-0.000^{* * *}$ & 851 & 7 & 0.13 \\
\hline & $(0.0001)$ & $(0.0)$ & & & \\
\hline
\end{tabular}


Table 6b. OLS cross-section estimation of Equation (62)

\begin{tabular}{|c|c|c|c|c|c|}
\hline & \multicolumn{5}{|c|}{ Positive and negative markups } \\
\hline & $a$ & $b$ & Firms & $>0$ & $R^{2}$ \\
\hline \multirow[t]{2}{*}{ Meat related products } & $0.002^{*}$ & -0.0000 & 33 & 9 & 0.16 \\
\hline & $(0.001)$ & $(0.0)$ & & $2(\mathrm{Li}>0)$ & \\
\hline \multirow[t]{2}{*}{ Food, tobacco and beverages } & $0.002^{* * *}$ & $-0.000^{* * *}$ & 125 & 23 & 0.14 \\
\hline & $(0.0005)$ & $(0.0)$ & & $4(\mathrm{Li}>0)$ & \\
\hline \multirow[t]{2}{*}{ Textiles and clothing } & $0.012^{* * *}$ & $-0.0001^{* * *}$ & 95 & 21 & 0.15 \\
\hline & $(0.003)$ & $(0.0)$ & & $2(\mathrm{Li}>0)$ & \\
\hline \multirow[t]{2}{*}{ Timber and paper } & $0.004^{* * *}$ & -0.000 & 50 & 3 & 0.37 \\
\hline & $(0.001)$ & $(0.0)$ & & & \\
\hline \multirow[t]{2}{*}{ Printing and Publishing } & $0.006^{* *}$ & -0.00003 & 48 & 4 & 0.06 \\
\hline & $(0.003)$ & $(0.0)$ & & $3(\mathrm{Li}>0)$ & \\
\hline \multirow[t]{2}{*}{ Chemicals } & $0.003^{* * *}$ & $-0.000^{* * *}$ & 70 & 11 & 0.18 \\
\hline & $(0.001)$ & $(0.0)$ & & $7(\mathrm{Li}>0)$ & \\
\hline \multirow[t]{2}{*}{ Plastic and rubber products } & $0.003^{* *}$ & -0.00001 & 43 & 5 & 0.08 \\
\hline & $(0.002)$ & $(0.0)$ & & $2(\mathrm{Li}>0)$ & \\
\hline \multirow[t]{2}{*}{ Non-mineral products } & $0.005^{* * *}$ & $-0.00002^{* * *}$ & 72 & 9 & 0.22 \\
\hline & $(0.001)$ & $(0.0)$ & & $1(\mathrm{Li}>0)$ & \\
\hline \multirow[t]{2}{*}{ Basic metal products } & $0.002^{* * *}$ & $-0.000^{* * *}$ & 37 & 2 & 0.34 \\
\hline & $(0.0004)$ & $(0.0)$ & & $1(\mathrm{Li}>0)$ & \\
\hline \multirow[t]{2}{*}{ Fabricated metal products } & $0.007^{* * *}$ & $-0.00004^{* * *}$ & 81 & 11 & 0.14 \\
\hline & $(0.002)$ & $(0.00002)$ & & $3(\mathrm{Li}>0)$ & \\
\hline \multirow[t]{2}{*}{ Industrial and agricultural equipment } & $0.002^{* *}$ & -0.000 & 74 & 13 & 0.05 \\
\hline & $(0.001)$ & $(0.0)$ & & $3(\mathrm{Li}>0)$ & \\
\hline \multirow[t]{2}{*}{ Office mach. and Electric materials } & $0.003^{* * *}$ & $-0.000^{* *}$ & 67 & 14 & 0.15 \\
\hline & $(0.001)$ & $(0.0)$ & & $6(\mathrm{Li}>0)$ & \\
\hline \multirow[t]{2}{*}{ Vehicles and transport equipment } & $0.001^{* * *}$ & $-0.000^{* * *}$ & 72 & 7 & 0.18 \\
\hline & $(0.0002)$ & $(0.0)$ & & $2(\mathrm{Li}>0)$ & \\
\hline \multirow[t]{2}{*}{ Furniture } & $0.010^{* *}$ & -0.00008 & 38 & 5 & 0.17 \\
\hline & $(0.005)$ & $(0.00006)$ & & $1(\mathrm{Li}>0)$ & \\
\hline \multirow[t]{2}{*}{ Leather, fur, footwear and Misc. } & $0.022^{* * *}$ & $-0.0003^{*}$ & 42 & 5 & 0.25 \\
\hline & $(0.008)$ & $(0.0002)$ & & $2(\mathrm{Li}>0)$ & \\
\hline \multirow[t]{2}{*}{ All firms } & $0.001^{* * *}$ & $-0.000^{* * *}$ & 947 & 102 & 0.09 \\
\hline & $(0.0001)$ & $(0.0)$ & & $6(\mathrm{Li}>0)$ & \\
\hline
\end{tabular}




\section{References}

[1] Bresnahan, T. F., (1989). "Empirical Studies of Industries with Market Power" in Schmalensee, R. and Willig, R. D. (eds.), Handbook of Industrial Organization, (North-Holland, New York).

[2] Corchón, L. (1994). "Comparative Statics for Aggregative Games: The Strong Concavity Case", Mathematical Social Sciences, 28, 151-165

[3] De Loecker, J, and F. Warzynski (2009). "Markups and Firm-Level Export Status" NBER Working Papers, 15198.

[4] Feenstra, R., and H. L. Kee (2008). "Export Variety and Country Productivity: Estimating the Monopolistic Competition Model with Endogenous Productivity", Journal of International Economics 74, 500-18.

[5] Hall, R.E. (1988): "The Relation between Price and Marginal Cost in the US Industry", Journal of Political Economy 96, 921-947.

[6] Kimw, D-W and C. R. Knittel (2006). "Biases in Static Oligopoly Model Evidence from the California Electricity Market", The Journal of Industrial Economics, 54, 4, 451-470.

[7] Konings, J. and H. Vandenbussche (2005a). "Antidumping Protection and Markups of Domestic Firms", Journal of International Economics, 65, 151165.

[8] Konings, J, P. Van Cayseele and F. Warzybski (2005b). "The Effects of Privatization and Competitive Pressure on Firms' Price-Cost Margins: Micro Evidence for Emerging Economies", The Review of Economics and Statistics, 87 (1), 124-134.

[9] Levinsohn, J. and A. Petrin (2003). "Estimating Production Functions Using Inputs to Control for Unobservables", Review of Economic Studies, $70(2), 317-341$.

[10] Lucas, R. (1985). Models of Business Cycles. Yrjo Jahnsson Lectures. Oxford, Basil Blackwell.

[11] Melitz, M. and G. Ottaviano (2008). "Market Size, Trade, and Productivity", Review of Economic Studies (2008) 75, 295-316. 
[12] Miravete, E. and L.-H Röller (2004). "Estimating Price-cost Markups Under Nonlinear Pricing Competition", Journal of the European Economic Association, 2, 2/3, 526-535.

[13] Moreno, L. and D. Rodríguez (2010a). "Export Activity, Persistence and Markups", Applied Economics, 42, 475-488.

[14] Moreno, L. \& D. Rodríguez (2010b). "Markups, Bargaining Power and Offshoring: An Empirical Assessment", MPRA Paper, No 23587.

[15] Olley, G. and A. Pakes (1996). "The Dynamics of Productivity in the Telecommunications Equipment Industry", Econometrica 64, 6, 1263-1297.

[16] Ray, D. and K. Ueda (1996). "Egalitarianism and Incentives". Journal of Economic Theory, 71, 324-348.

[17] Roeger, W. (1995): "Can Imperfect Competition Explain the Difference between Primal and Dual Productivity Measures? Estimates for U.S. Manufacturing", Journal of Political Economy, 103, 2, 316-330.

[18] Segura, J., J.C. Fariñas, J. Jaumandreu, C. Martín, J. L. Calvo, J.M ${ }^{a}$ Labeaga, $\mathrm{M}^{a}$ J. Lorenzo, E. Huergo, A. Martín Marcos, J. Velázquez, C. de la Iglesia, E. Martínez and D. Rodríguez (1992). Un Panorama de la Industria Española. MICYT. Madrid.

[19] Spence, M., 1976. "Product Selection, Fixed Costs, and Monopolistic Competition", Review of Economic Studies, 43, 217-235. 